\title{
Drilling k-wires, what about the osteocytes? An experimental study in rabbits
}

\author{
Bas B. G. M. Franssen · Paul J. van Diest • \\ Arnold H. Schuurman · Moshe Kon
}

Received: 8 March 2007 / Published online: 28 June 2007

(C) Springer-Verlag 2007

\begin{abstract}
Introduction The function of osteocytes regarding osteonecrosis has been underestimated for a long time. Recently it has been suggested that apoptosis of osteocytes results in strong osteoclastic bone resorption. Death of osteocytes due to drilling may therefore increase the risk of K-wire loosening. The purposes of our in vivo study were to assess the minimal drill time needed to notice disappearance of osteocytes and to measure the distance of the empty osteocyte lacunae surrounding the drill tract in relation with the insertion time, directly and 4 weeks after drilling Kirschner (K-) wires into the femur and tibia of rabbits.

Materials and methods Trocar tipped K-wires $(70 \mathrm{~mm}$ length and $0.6 \mathrm{~mm}$ thickness) were drilled into the femur and tibia of 14 New Zealand white rabbits [mean body weight $2.81 \mathrm{~kg}(2.66-3.09 \mathrm{~kg})]$. Six rabbits were terminated following surgery $(t=0)$ and eight rabbits were terminated 4 weeks $(t=4)$ after surgery. Following termination, hematoxylin and eosin stained sections were cut from femur and tibia until the drill hole was visible. The sections were evaluated under a light microscope for the presence or absence of osteocytes in osteocyte lacunae surrounding the drill holes.
\end{abstract}

B. B. G. M. Franssen $(\bowtie) \cdot$ A. H. Schuurman · M. Kon Department of Plastic, Reconstructive and Hand Surgery, University Medical Center Utrecht, Room G04.122, PO Box 85500, 3508 GA, Utrecht, The Netherlands e-mail: bbgmfranssen@gmail.com

P. J. van Diest

Department of Pathology, University Medical Center Utrecht, Room H04.312, PO Box 85500, 3508 GA,

Utrecht, The Netherlands
Results All osteocyte lacunae were empty around the Kwires in 50 and $87 \%$ of the cases, directly and 4 weeks after the surgery, respectively. The osteocytes disappeared especially beyond a drilling time of $37 \mathrm{~s}(P=0.011)$ and $27 \mathrm{~s}$ $(P=0.008)$ at $t=0$ and $t=4$, respectively. Furthermore, a significantly positive correlation was seen between the distances of the empty osteocyte lacunae surrounding the drill holes in relation with time at $t=0(P=0.008)$ and $t=4$ $(P=0.000)$.

Conclusion Although only drilling without cooling was studied, short drilling times may prevent the disappearance of osteocytes in case cooling is not used in clinical practice as is the case in percutaneous $\mathrm{K}$-wire insertion.

Keywords Animal $\cdot$ Kirschner wire $\cdot$ Drilling · Histology $\cdot$ Insertion time

\section{Introduction}

Experiments concerning thermal damage to bone tissue due to drilling Kirschner wires (K-wires) show several variables interfering with heat generation [7, 9-14, 32]. These variables can be categorized into three groups: drilling technique, K-wire characteristics and external factors. The drilling technique is a subtle balance between drilling speed, insertion time and pressure [1, 2, 5, 30, 31, 34]. The characteristics of $\mathrm{K}$-wires differ in diameter and $\mathrm{K}$-wire tip $[17,23,29]$. The main external factor is irrigation with a water spray during drilling $[3,20,24,36]$.

It is believed that critical temperature for bone injury is around $56^{\circ} \mathrm{C}$ because alkaline phosphatase denaturates at this temperature. Osteocytes, however, may even be more sensitive to heat [23, 24]. Eriksson [9, 10, 12] observed that a temperature of $47^{\circ} \mathrm{C}$ for only $1 \mathrm{~min}$ results in bone resorption. 
Bone is capable of remodeling by bone resorbing osteoclasts, bone forming osteoblasts and osteocytes [15, 19, 22, 26]. The latter differentiate out of osteoblasts which have ceased bone production and have become embedded in the bone matrix, in vacuoles cushioned by fluid and large molecules, forming a network $[8,15,19,22,25]$. Despite the fact that the osteocytes are the major constituents of bone, their role in bone resorption regulation has remained controversial for a long time $[4,16,21,22,27]$. In the past decade, however, understanding of osteocyte physiology has increased dramatically and it has become clear that osteocytes play an important role in bone remodeling [6, $15,18,25,26,35]$. Now we know that micro damage to bone, e.g. by drilling, is associated with an increase in osteocyte death by apoptosis [25]. This process triggers local bone resorption resulting in $\mathrm{K}$-wire loosening, because death of osteocytes turns off the inhibition of osteoclasts [6, $15,16,22,25,35]$.

The status of osteocytes after drilling into bone has been investigated before. Thompson [33] describes the absence of osteocytes as an acute cellular reaction, which increases in severity with increase of drilling speed. Pallan et al. [28] continued Thompson's [33] work and describes the delayed cellular changes in bone after pin insertion which were left in situ for maximum 10 weeks. He also concluded that higher speeds produce relatively higher temperatures and increased tissue response after a long time period [28].

It is well known that in clinical daily practice $\mathrm{K}$-wires are often drilled without proper cooling because most drilling devices do not have an incorporated cooling system and therefore cooling has to be done manually. In case percutaneous drilling is performed, the cooling effect on bone is minimal because of the surrounding soft tissues. An in vivo study was therefore designed which simulated daily practice concerning $\mathrm{K}$-wire drilling to analyze the absence of osteocytes directly $(t=0)$ and 4 weeks $(t=4)$ after insertion. Our first aim was to measure the minimal drill time needed to notice disappearance of osteocytes. The second aim was to measure the distance of the disappeared osteo- cytes around the periphery of the drill holes in relation to drilling time.

\section{Materials and methods}

Animals and anesthesia

A total of 14 healthy, New Zealand white rabbits of female sex weighing a mean of $2.81 \mathrm{~kg}(2.66-3.09 \mathrm{~kg})$ were used in this investigation. The rabbits were solely housed on a $12 \mathrm{~h} / 12 \mathrm{~h}$ (light/dark) cycle and provided with standard diet food and water ad libitum. All animals were housed in the Central Animal Laboratory, Utrecht University, Utrecht, The Netherlands and received care in compliance with the European Convention Guidelines.

The animals were pre-anesthetized with a combination of methadone ( $10 \mathrm{mg} / \mathrm{ml}$ at a dose of $2.5-5.0 \mathrm{mg}$ i.m.), ventraquil $(10 \mathrm{mg} / \mathrm{ml}$ at a dose of $2.5-5.0 \mathrm{mg}$ i.m. $)$ and etomidaat $(2 \mathrm{mg} / \mathrm{ml}$ at a dose of $2.0-8.0 \mathrm{mg}$ i.v. $)$.

After introduction of anesthesia the rabbits were cuffed and mechanically ventilated with $\mathrm{O}_{2}: \mathrm{N}_{2} \mathrm{O}$, proportion $1: 1$, and $2 \%$ isoflurane. During the surgical procedure methadone (2.0-5.0 mg i.v.) was given. At the end of the operation nalbuphine $(10 \mathrm{mg} / \mathrm{ml}$ at a dose of $1.0-2.0 \mathrm{mg} / \mathrm{kg}$ i.v. $)$ was administered. After surgery the rabbits were housed at the intensive care for the rest of the day and night. At the end of the study the rabbits were euthanized by an i.v. overdose of pentobarbital.

\section{Surgical technique}

An operation device was created by the first author (Fig. 1). The operation device consists of a base plate. On this base plate, a dynamic plate was fixed which could be moved up or down. In front of the entire length of this dynamic plate a sideways moving slide was fixed on the base plate. On this sideways moving slide another back-forward slide including the drill was fixed. Forward movement of the drill was initiated using a $1.5 \mathrm{~kg}$ weight.
Fig. 1 Operation device consisting of a base plate with a slide for sideways movement on top of this. On this slide another back-forward slide with a drill was fixed. The forward movement was initiated by a weight of $1.5 \mathrm{~kg}$. Another dynamic plate was fixed on the base of the plate to move up and down. During surgery, the rabbit was fixed on this dynamic plate

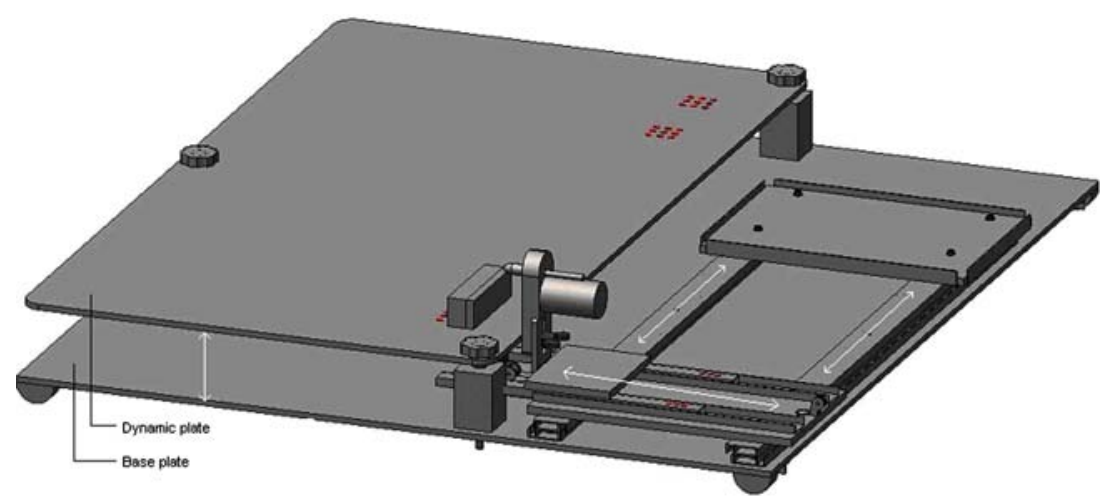


During surgery the rabbit was fixed on the dynamic plate. This plate made it possible that the femur or tibia were on the same height as the $\mathrm{K}$-wire. The sideways moving slide was responsible for the exact position of the Kwire in front of the femur or tibia.

After the rabbits were preanesthetized, X-rays were made to exclude deformities. Thereafter the animal's hind limb was carefully shaved and prepared with a povidoneiodine solution. After this procedure, the hind limb was fixed on the testing machine. With the animal surgically draped, a straight-line skin incision was made on the lateral aspect of the femur extending from just below the anteriorinferior spine to the distal femur, followed by a straight-line skin incision on the lateral aspect of the tibia extending from just below the joint line proximally to about the joint line distally.

Dissection was carried out down to the periostium. Synthes Trocar tipped K-wires of $70 \mathrm{~mm}$ length and $0.6 \mathrm{~mm}$ thickness were drilled through the diaphysis. One K-wire was drilled into the femur and one into the tibia. Drilling was performed by a rotary engine fixed at 1,200 rpm. This is the maximum drilling speed used in our daily practice. Cooling was not performed. After insertion, the K-wires were cut short and the K-wire ends were bent to the cortex. After the wounds were closed in layers, X-rays were made to check the position of the K-wires and the condition of the bone. Insertion time could be measured very accurately by analyzing the operations recorded on video camera. All the experiments were performed by the same investigator.

\section{Histological technique}

After termination, the femur and tibia were removed from the hind limb and fixed in $4 \%$ formaldehyde solution. They were then decalcified, cut transversely next to the K-wire hole, after the K-wire was removed gently by a pair of tweezers, and embedded in paraffin according to standard procedures. Four micrometer thick serial sections were cut until the drill hole was visible, stained with hematoxylin and eosin and evaluated under a light microscope at $400 \times$ magnification for the presence or absence of osteocytes in the osteocyte lacunae surrounding the drill holes by a single investigator. The best section was used for evaluation. The distance over which the osteocytes had disappeared perpendicular to the drill holes was measured with an interactive morphometry device (Q-PRODIT, Leica, Cambridge, UK). In each section, four distances from the drill hole to the first osteocyte bearing lacuna were measured and averaged.

\section{Statistics}

Pearson's Chi-square test was used to determine the drilling time needed for osteocytes to disappear. Pearson correla- tion was used to highlight any significant correlation between the drilling time and the distance of the disappeared osteocytes surrounding the drill holes. A $P$-value $<0.05$ was considered statistically significant. The data were analyzed using SPSS 12.0.1 for windows.

\section{Results}

After surgery $(t=0)$ six rabbits were terminated. Both hind limbs were used resulting in 24 assessments. From the remaining eight rabbits only one hind limb was operated. Four weeks later at termination this resulted in 16 assessments $(t=4)$. Two $t=0$ and one $t=4$ assessments were lost because no sections could be produced showing the drill hole, leaving $22 t=0$ and $15 t=4$ assessments.

Histological response to drilling was seen in most sections next to the drill hole (Fig. 2). At $t=0$ and $t=4$, all osteocyte lacunae next to the drill holes were empty in 11/ $22(50.0 \%)$ and 13/15 (86.7\%) of bones, respectively. At $t=4$, a drilling time longer than $27 \mathrm{~s}$ resulted in a significant loss of osteocytes surrounding the drill holes $(P=0.008)$. At $t=0$, a drilling time longer than $37 \mathrm{~s}$ resulted in a significant loss of osteocytes surrounding the drill holes $(P=0.011)$.

A statistically significant positive correlation was seen between the distance of the empty osteocyte lacunae surrounding the drill hole in relation with drilling time, directly $(P=0.008$, Fig. 3a) and 4 weeks after K-wire insertion $(P<0.000$, Fig. 3b).

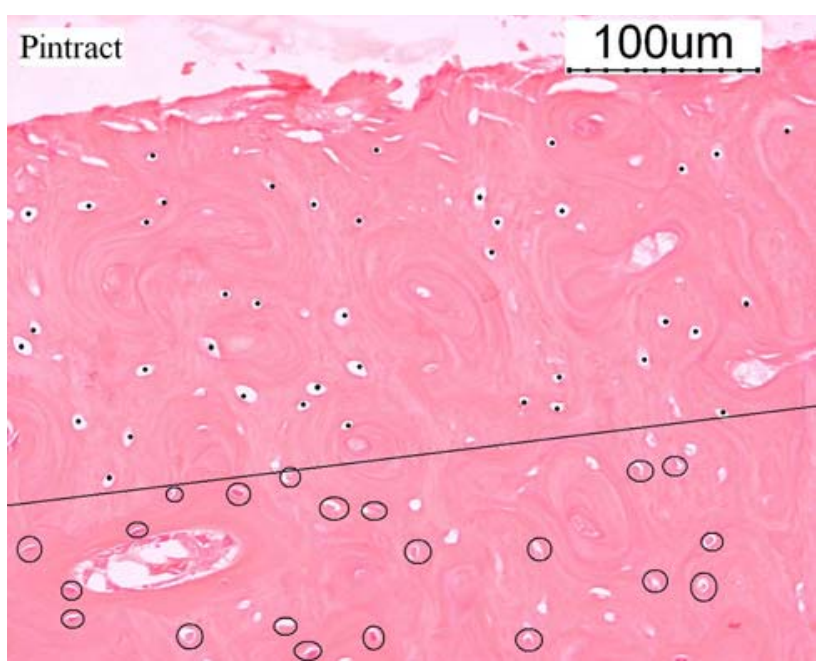

Fig. 2 Status of osteocytes due to K-wire drilling at 1,200 rpm. Disappeared osteocytes due to drilling are marked by a dot. The osteocytes are encircled. The dotted line indicates the border between the present and disappeared osteocytes (hematoxylin and eosin) 

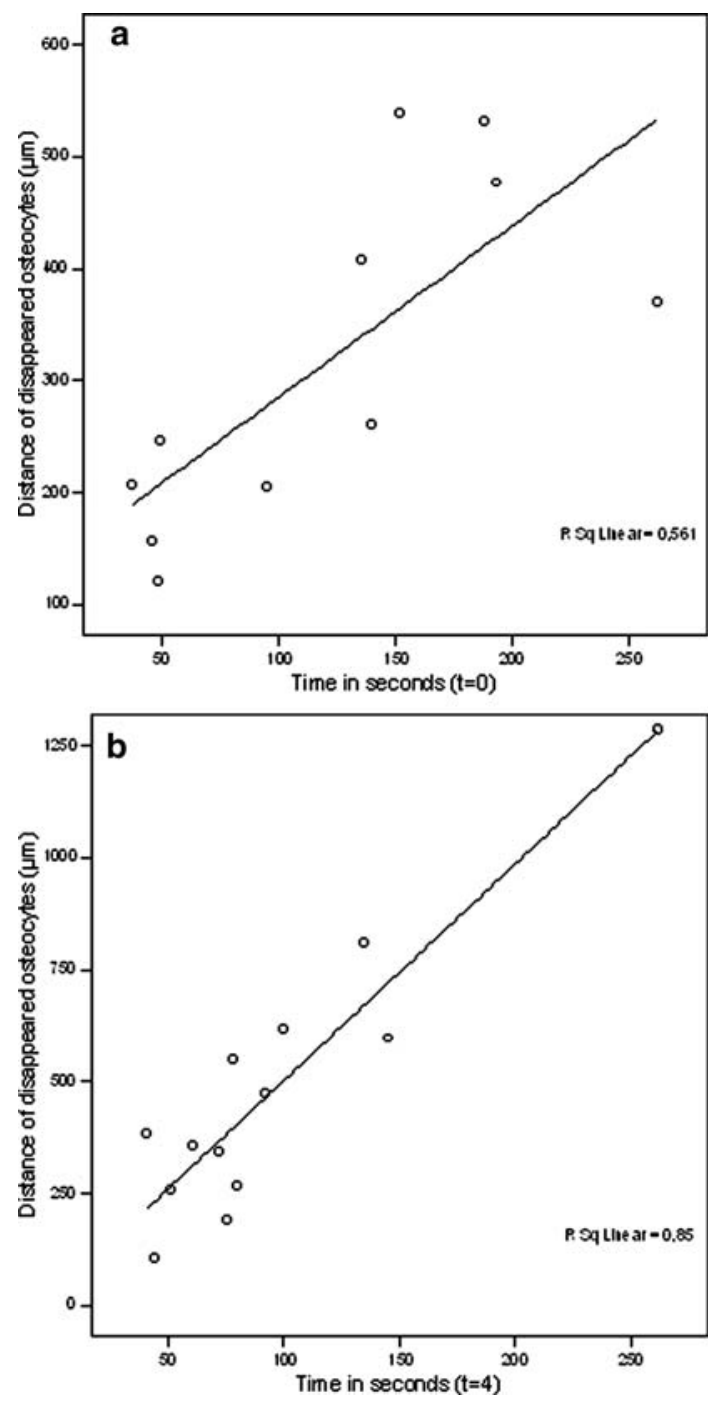

Fig. 3 a Distance of empty osteocyte lacunae, in micrometers, surrounding the drill hole in correlation with drilling time, in seconds, at $t=0$. b Distance of empty osteocyte lacunae, in micrometers, surrounding the drill hole in correlation with drilling time, in seconds, at $t=4$

\section{Discussion}

The two most important findings of this experiment are that (1) osteocytes disappear especially beyond a drilling time of $27 \mathrm{~s}$ and (2) that there is a positive correlation between the distance of the empty osteocyte lacunae in relation with drilling time.

As far as we know there are no experiments studying the presence/absence of osteocytes while using drilling time as a variable. Therefore it is interesting to notice that our results, representing daily practice by using a drilling speed of $1,200 \mathrm{rpm}$, clearly indicate that osteocytes disappear after a drilling time above $27 \mathrm{~s}$ in this animal model, when no cooling is used. Pallan [28] and Thompson[33] however, noticed absence of osteocytes already after a drilling time varying from 5 to $12 \mathrm{~s}$. The limitation of their experiments is that the insertion force was not standardized. That could be a possible factor explaining the difference in insertion time with matching histological changes.

The effect on osteocytes in our study was more pronounced 4 weeks after insertion compared to the effect on osteocytes directly after surgery. This confirms the results from Thompson [33] where the effect on osteocytes was more pronounced $72 \mathrm{~h}$ after the operation than at either 24 or $48 \mathrm{~h}$. Apparently, not all damage to osteocytes is acute and microscopically visible, directly after $\mathrm{K}$-wire insertion. This can be explained by the study of Eriksson et al. [13]. They compared histology and histochemistry for detection of bone viability directly after surgery. The histological sections revealed a $200 \mu \mathrm{m}$ wide zone of empty osteocyte lacunae around the periphery of the drill hole while histochemistry of the same bone specimens showed a zone of $500 \mu \mathrm{m}$ lacking diaphorase enzyme activity. This indicates that the empty osteocyte lacunae directly after surgery underestimates the extent of the drilling trauma and becomes clear as time passes. Neovascularisation is probably a reason for the increase of osteocytes disappearance in time. During heating, due to drilling, blood flow will stop in minor vessels preventing the clearance of the osteocyte lacunae [10, 13]. After neovascularisation the osteocyte lacunae can be cleared finally.

Our study also showed an interesting positive correlation between the distance of the empty osteocyte lacunae in relation with time. The zones of disappeared osteocytes varied from 106 to $1,285 \mu \mathrm{m}$ and the drilling times from 41 to $262 \mathrm{~s}$. A correlation between drill time and distance was not shown before. What we do know is that Eriksson et al. showed a $200 \mu \mathrm{m}$ wide zone of empty osteocyte lacunae around the periphery of the hole after drilling into femurs of New Zealand white rabbits while conventional irrigation was administered[13]. These results are difficult to compare because Eriksson et al. did not measure time, irrigated with saline, did not standardize the insertion force and drilled with a running speed of 20,000 rpm. Furthermore, Pallan [28] showed that the histological changes, including absence of osteocytes, were never apparent more than 250 to $500 \mu \mathrm{m}$ from the pins [28]. Like Eriksson they did not standardize insertion force and drilling time varied from 5 to $12 \mathrm{~s}$.

No osteoclastic activity was noticed in the already existing cortex. This was expected as Pallan [28] hardly noticed osteoclastic activity after 6 weeks, and only slight osteoclastic activity after 8 and 10 weeks and our experiments covered a time span of only 4 weeks.

We are convinced that delayed tissue response corresponds with late $\mathrm{K}$-wire loosening seen in daily practice. Although we did not compare drilling, with and without 
cooling, this study demonstrates the need for a short drill time, less than $27 \mathrm{~s}$ to prevent the disappearance of osteocytes and to limit the bone resorption cascade.

Acknowledgments The authors are grateful for the financial support which this project has received from the Anna Foundation, Leiden, The Netherlands. Full approval from the Utrecht University Committee for Experiments on Animals was obtained and was in accordance with the Dutch laws on experimental animals.

\section{Reference}

1. Abouzgia MB, James DF (1997) Temperature rise during drilling through bone. Int J Oral Maxillofac Implants 12:342-353

2. Abouzgia MB, Symington JM (1996) Effect of drill speed on bone temperature. Int J Oral Maxillofac Surg 25:394-399

3. Benington IC, Biagioni PA, Briggs J, Sheridan S, Lamey PJ (2002) Thermal changes observed at implant sites during internal and external irrigation. Clin Oral Implants Res 13:293-297

4. Boabaid F, Cerri PS, Katchburian E (2001) Apoptotic bone cells may be engulfed by osteoclasts during alveolar bone resorption in young rats. Tissue Cell 33:318-325

5. Brisman DL (1996) The effect of speed, pressure, and time on bone temperature during the drilling of implant sites. Int J Oral Maxillofac Implants 11:35-37

6. Clark WD, Smith EL, Linn KA, Paul-Murphy JR, Muir P, Cook ME (2005) Osteocyte apoptosis and osteoclast presence in chicken radii 0-4 days following osteotomy. Calcif Tissue Int 77:327-336

7. Cordioli G, Majzoub Z (1997) Heat generation during implant site preparation: an in vitro study. Int J Oral Maxillofac Implants 12:186-193

8. Cormack DH (1993) Essential histology. 1st edn. J. B. Lippincott, Philadelphia

9. Eriksson A, Albrektsson T, Grane B, McQueen D (1982) Thermal injury to bone. A vital-microscopic description of heat effects. Int J Oral Surg 11:115-121

10. Eriksson AR, Albrektsson T (1983) Temperature threshold levels for heat-induced bone tissue injury: a vital-microscopic study in the rabbit. J Prosthet Dent 50:101-107

11. Eriksson AR, Albrektsson T, Albrektsson B (1984) Heat caused by drilling cortical bone. Temperature measured in vivo in patients and animals. Acta Orthop Scand 55:629-631

12. Eriksson RA, Albrektsson T (1984) The effect of heat on bone regeneration: an experimental study in the rabbit using the bone growth chamber. J Oral Maxillofac Surg 42:705-711

13. Eriksson RA, Albrektsson T, Magnusson B (1984) Assessment of bone viability after heat trauma. A histological, histochemical and vital microscopic study in the rabbit.Scand. J Plast Reconstr Surg $18: 261-268$

14. Field JR, Sumner-Smith G (2002) Bone blood flow response to surgical trauma. Injury 33:447-451

15. Gu G, Mulari M, Peng Z, Hentunen TA, Vaananen HK (2005) Death of osteocytes turns off the inhibition of osteoclasts and triggers local bone resorption. Biochem Biophys Res Commun 335:1095-1101
16. Heino TJ, Hentunen TA, Vaananen HK (2002) Osteocytes inhibit osteoclastic bone resorption through transforming growth factorbeta: enhancement by estrogen. J Cell Biochem 85:185-197

17. Khanna A, Plessas SJ, Barrett P, Bainbridge LC (1999) The thermal effects of Kirschner wire fixation on small bones. J Hand Surg [Br] 24:355-357

18. Klein DM, Belsole RJ (2000) Percutaneous treatment of carpal, metacarpal, and phalangeal injuries. Clin Orthop Relat Res 375:116-125

19. Klein-Nulend J, Bacabac RG, Mullender MG (2005) Mechanobiology of bone tissue. Pathol Biol (Paris) 53:576-580

20. Lavelle C, Wedgwood D (1980) Effect of internal irrigation on frictional heat generated from bone drilling. J Oral Surg 38:499503

21. Li G, Dickson GR, Marsh DR, Simpson H (2003) Rapid new bone tissue remodeling during distraction osteogenesis is associated with apoptosis. J Orthop Res 21:28-35

22. Maejima-Ikeda A, Aoki M, Tsuritani K, Kamioka K, Hiura K, Miyoshi T, Hara H, Takano-Yamamoto T, Kumegawa M (1997) Chick osteocyte-derived protein inhibits osteoclastic bone resorption. Biochem J 322(Pt 1):245-250

23. Matthews LS, Green CA, Goldstein SA (1984) The thermal effects of skeletal fixation-pin insertion in bone. J Bone Joint Surg Am 66:1077-1083

24. Matthews LS, Hirsch C (1972) Temperatures measured in human cortical bone when drilling. J Bone Joint Surg Am 54:297-308

25. Noble B (2003) Bone microdamage and cell apoptosis. Eur Cell Mater 6:46-55

26. Noble BS, Peet N, Stevens HY, Brabbs A, Mosley JR, Reilly GC, Reeve J, Skerry TM, Lanyon LE (2003) Mechanical loading: biphasic osteocyte survival and targeting of osteoclasts for bone destruction in rat cortical bone. Am J Physiol Cell Physiol 284:934-943

27. Noble BS, Reeve J (2000) Osteocyte function, osteocyte death and bone fracture resistance. Mol Cell Endocrinol 159:7-13

28. Pallan FG (1960) Histological changes in bone after insertdon of skeletal fixation pins. J Oral Surg Anesth Hosp Dent Serv 18:400_ 408

29. Piska M, Yang L, Reed M, Saleh M (2002) Drilling efficiency and temperature elevation of three types of Kirschner-wire point. J Bone Joint Surg Br 84:137-140

30. Reingewirtz Y, Szmukler-Moncler S, Senger B (1997) Influence of different parameters on bone heating and drilling time in implantology. Clin Oral Implants Res 8:189-197

31. Sharawy M, Misch CE, Weller N, Tehemar S (2002) Heat generation during implant drilling: the significance of motor speed. J Oral Maxillofac Surg 60:1160-1169

32. Shin HC, Yoon YS (2006) Bone temperature estimation during orthopaedic round bur milling operations. J Biomech 39:33-39

33. Thompson HC (1958) Effect of drilling into bone. J Oral Surg Anesth Hosp Dent Serv 16:22-30

34. van Egmond DB, Hovius SE, van der Meulen JC, den Ouden A (1994) Heat recordings at tips of Kirschner wires during drilling through human phalanges. J Hand Surg [Am] 19:648-652

35. Xing L, Boyce BF (2005) Regulation of apoptosis in osteoclasts and osteoblastic cells. Biochem Biophys Res Commun 328:709-720

36. Yacker MJ, Klein M (1996) The effect of irrigation on osteotomy depth and bur diameter. Int J Oral Maxillofac Implants 11:634-638 